Check for updates

Cite this: RSC Adv., 2019, 9, 39893

Received 20th August 2019

Accepted 22nd November 2019

DOI: $10.1039 / c 9 r a 06547 d$

rsc.li/rsc-advances

\section{High pressure extraction of bioactive diterpenes from the macroalgae Bifurcaria bifurcata: an efficient and environmentally friendly approach $\dagger$}

\author{
Adriana C. S. Pais, ${ }^{a}$ Carlos A. Pinto, ${ }^{b}$ Patrícia A. B. Ramos, ${ }^{\text {ab }}$ Ricardo J. B. Pinto, (D) ${ }^{a}$ \\ Daniela Rosa, ${ }^{C}$ Maria F. Duarte, ${ }^{c d}$ M. Helena Abreu, ${ }^{e}$ Silvia M. Rocha, ${ }^{b}$ \\ Jorge A. Saraiva, (D ${ }^{\text {b }}$ Armando J. D. Silvestre (iD a and Sónia A. O. Santos (DD *a
}

\begin{abstract}
The brown macroalgae Bifurcaria bifurcata have gained special attention due to their ability to biosynthesize linear diterpenes (rarely found in other species). However, the conventional extraction methods normally used to extract these compounds involve organic solvents and often high temperatures, leading to the degradation of thermo-labile compounds. In this context, the main objective of this work was to study and optimize for the first time the extraction of diterpenes from B. bifurcata through an environmentally friendly methodology, namely, high pressure extraction (HPE) using ethanol: water. This was compared with conventional Soxhlet extraction, using dichloromethane. Box-Behnken design was employed to evaluate the linear, quadratic, and interaction effects of 3 independent variables (pressure $\left(X_{1}\right)$, ethanol percentage $\left(X_{2}\right)$, and time of extraction $\left(X_{3}\right)$ ) on response variables (extraction yield and diterpenes content ( $\mathrm{mg} \mathrm{g}^{-1}$ of extract and $\mathrm{mg} \mathrm{kg}^{-1}$ of dry weight)) and the optimal extraction conditions ( $X_{1}$ : $600 \mathrm{MPa} ; X_{2}: 80 \% ; X_{3}: 5 \mathrm{~min}$ ) were estimated by response surface methodology (RSM). B. bifurcata extract obtained under HPE optimal conditions showed a diterpenes content $\left(612.2 \mathrm{mg} \mathrm{g}^{-1}\right.$ of extract) 12.2 fold higher than that obtained by conventional extraction $\left(50.1 \mathrm{mg} \mathrm{g}^{-1}\right.$ of extract). The HPE extract, obtained under optimal conditions, showed antioxidant and antibacterial (against Staphylococcus aureus) activities considerably higher than the Soxhlet extract, and also presented a promising synergic effect with antibiotics, improving the antibiotic efficacy against $S$. aureus. In conclusion, these results indicate that HPE is a promising methodology, compared to conventional methodologies to obtain linear diterpene rich extracts from $B$. bifurcata with great potential to be exploited in pharmaceutical or biomedical applications.
\end{abstract}

\section{Introduction}

Bioactive natural compounds from marine sources have gained increased interest. ${ }^{1}$ Bifurcaria bifurcata is a brown macroalga that thrives, year-round, in the intertidal areas (the lower shore, rockpools and mid-shore) along the coast of the Northern Atlantic, from Morocco (southern limit) to north-western Ireland (northern limit). ${ }^{2-4}$ The chemical composition of this brown

${ }^{a}$ CICECO-Aveiro Institute of Materials, Department of Chemistry, University of Aveiro, Campus de Santiago, 3810-193 Aveiro, Portugal.E-mail: santos.sonia@ua.pt ${ }^{b}$ QOPNA/LAQV \& REQUIMTE, Department of Chemistry, University of Aveiro, Campus de Santiago, 3810-193 Aveiro, Portugal

${ }^{c}$ Centro de Biotecnologia Agrícola e Agro-Alimentar do Alentejo (CEBAL), Instituto Politécnico de Beja (IPBeja), Beja, 7801-908, Portugal

${ }^{d}$ Instituto de Ciências Agrárias e Ambientais Mediterrânicas (ICAAM), Universidade de Évora, Pólo da Mitra, 7002-554 Évora, Portugal

${ }^{e}$ ALGAplus-Prod. e Comerc. De Algas e Seus Derivados, Lda., Ílhavo, 3830-196, Portugal

$\dagger$ Electronic supplementary information (ESI) available. See DOI: 10.1039/c9ra06547d macroalga has gained particular attention, due to the abundance of a variety of acyclic diterpenes. ${ }^{5-12}$ Compared to their cyclic counterparts, these linear diterpenes are relatively quite rare in nature, ${ }^{2}$ yet quite interesting since a vast range of promising bioactivities have been recognized for them. ${ }^{2,3,7,8,13-15}$ Recently, Santos et al. ${ }^{5}$ demonstrated the antioxidant, anti-inflammatory and antibacterial activities of B. bifurcata lipophilic extracts, mainly composed of linear diterpenes. In addition, a promising synergism was observed when these extracts were used together with antibiotic families of major clinical importance. ${ }^{5}$

In general, this species could be a promising source of bioactive molecules useful for pharmaceutical, biomedical or even cosmetic industries. ${ }^{3,5}$ Nonetheless, the commonly used conventional extraction methodologies involve the use of large amounts of organic solvents, often toxic to humans and harmful to environment, such as dichloromethane ${ }^{5}$ or chloroform $^{\mathbf{1 6}}$ which represents a major limitation to the industrial exploitation of $B$. bifurcata diterpenes rich extracts. In addition, these extraction methods have demonstrated poor selectivity as at the same time require long operation times frequently at high 
temperatures, which can induce the degradation of thermolabile compounds. ${ }^{\mathbf{1 3 , 1 4}}$ Therefore, the evaluation and optimization of sustainable, economically viable and efficient methodologies to extract diterpenes from $B$. bifurcata macroalgae is an important challenge.

High pressure extraction (HPE) has been one of the emerging technologies that has been successfully exploited in the extraction of bioactive compounds from natural raw materials. ${ }^{17,18}$ HPE provides a large differential pressure between the interior and exterior of the cells, which causes cell walls and membranes structural damages, increasing their permeability and thus enhancing compounds dissolution in the extraction media. ${ }^{17}$ Additionally, HPE technology, usually performed at room temperature, presents a higher rate and efficiency of extraction than conventional methods, allowing to use safe solvents even presenting lower selectivity. Furthermore, this extraction methodology can be faster, with higher safety and energetically efficient. ${ }^{17,19}$ Although a major limitation of HPE has been associated with the high capital and equipment costs, the perspective for an expansion of HPE implementation in the near future is expected to lead to a decrease in costs. Actually, HP technology has been adopted quickly as reflected by the increased number of units installed. ${ }^{20,21}$

Although some studies have endorsed the use of HPE to extract lipophilic components (namely fatty acids and terpenes) from natural sources, ${ }^{18,19,22-26}$ no studies have been reported so far concerning the HPE of diterpenes. In addition, HPE has been only exploited in macroalgae to extract higher molecular weight components, namely sulfated polysaccharides from Sargassum muticum. ${ }^{27}$

In the present work the feasibility of HPE using ethanol :water mixtures to extract diterpenes from $B$. bifurcata macroalga was studied for the first time. Besides, the process parameters of HPE were optimized by both Box-Behnken design and response surface methodology (RSM). As final output of this work, the higher efficiency of HPE to recover diterpenes from $B$. bifurcata, as well as the higher antioxidant and antibacterial activities and synergism with different antibiotics of the extract obtained, compared with those previously described are demonstrated.

\section{Materials and methods}

\subsection{Sample preparation}

The company ALGAplus, Produção e Comercialização de Algas e seus derivados, Lda. was responsible for the collection and preprocessing of algal samples. B. bifurcata (batch B1.2643.08F), was harvested in November 2013, at Aguda Beach $\left(41^{\circ} 2^{\prime} 38^{\prime \prime} \mathrm{N}\right.$, $8^{\circ} 39^{\prime} 10^{\prime \prime} \mathrm{W}$ ), region of Oporto, Portugal. Processing consisted in washing the biomass with running tap water and then with distilled water. Samples were preserved at $-20{ }^{\circ} \mathrm{C}$ and then freeze-dried and milled at the laboratory of University of Aveiro.

\subsection{Conventional extraction}

For comparative purposes, three aliquots ( $5 \mathrm{~g}$ ) of lyophilized macroalgae samples were Soxhlet extracted with dichloromethane $(160 \mathrm{~mL})$, for $9 \mathrm{~h}$, following a procedure described before. ${ }^{5}$ The solvent was evaporated to dryness and the extracts were weighed. The results are expressed in percent of dry weight (dw) material (w/w, \%).

\subsection{High pressure extraction}

Each aliquot ( $5 \mathrm{~g}$ ) of lyophilized macroalgae was dispersed in $50 \mathrm{~mL}$ of solvent (ethanol : water, as described in 2.3.1 and 2.3.2 sub-topics) and placed in a double packaged in lowpermeability polyamide-polyethylene bags, which were heatsealed under vacuum. The bags containing the biomass and solvent mixtures were subject to HPE under different time periods and pressures according to the established extraction conditions (Tables 2 and 3). HPE were performed in a hydrostatic press (Hyperbaric 55, Hyperbaric, Burgos, Spain), which has a pressure vessel of $200 \mathrm{~mm}$ inner diameter and $2.0 \mathrm{~mm}$ length with a maximum operating pressure of $600 \mathrm{MPa}$.

After HPE, the aqueous/ethanol extracts and the remaining residue were removed from the bags and filtered through a glass filter funnel (porosity 3). Ethanol was evaporated and the extracts were frozen at $-80{ }^{\circ} \mathrm{C}$ until freeze-drying. Then, and similarly to the Soxhlet extract, the extraction yield (EY) was determined as weight percentage (w/w, \%) of dried extract.

2.3.1 Preliminary experiments. Preliminary experiments were carried out (Table 2), in order to determine which independent variables would have an effect on HPE, as well as their range of values. The solid/liquid ratios used were $1: 10$ (5 g of dry macroalgae in $50 \mathrm{~mL}$ of aqueous/ethanol solution). The extraction time was $15 \mathrm{~min}$.

2.3.2 Design of experiments. A Box-Behnken design was employed to determine the optimal extraction conditions for HPE of diterpenes from B. bifurcata. Based on the preliminary results, their main factors were chosen (pressure, ethanol percentage and time).

Table 3 presents the Box-Behnken design with three independent variables, designated as $X_{1}, X_{2}, X_{3}$, at three levels, coded $+1,0,-1$ for high, intermediate and low values, respectively: namely extraction pressure $\left(X_{1}: 0.1,300\right.$ and $\left.600 \mathrm{MPa}\right)$, ethanol percentage $\left(X_{2}: 40,60\right.$ and $\left.80 \%\right)$ and extraction time $\left(X_{3}: 5,17.5\right.$ and $30 \mathrm{~min}$ ). A solid/liquid ratio of $1: 10$ was used. EY and the diterpenes content (DC) (expressed as milligram per gram of extract and milligram per kilogram of $d w$ macroalgae) were used as response variables to evaluate the influence of the different levels of independent variables combined.

The response surface design consisted in 15 runs in randomized order, to minimize the effects of unexpected variability in the observed responses, ${ }^{27}$ with three replicates in the centre point to estimate the pure error sum of squares (Table 3 ).

A full quadratic model was used to fit the data according to eqn (1):

$$
Y=\beta_{0}+\sum_{i=1}^{3} \beta_{i} X_{i}+\sum_{i=1}^{3} \beta_{i i} X_{i}^{2}+\sum_{i=1}^{2} \sum_{j=1+1}^{3} \beta_{i j} X_{i} X_{j}
$$

where $Y$ is the predicted response, $\beta_{0}, \beta_{i}, \beta_{i i}$ and $\beta_{i j}$ are coefficients in the intercept, linear, quadratic and interaction terms, respectively, and $X_{i}, X_{j}$ are the independent variables. 
Analysis of variance (ANOVA) for response surface quadratic model validation was performed, and the test for significance of each term to test for goodness of fit was conducted at $P<0.05$. The design construction and analysis were achieved through Minitab 18 (Minitab Statistical Software, Pennsylvania State University, State College, PA) software.

\subsection{Diterpenes analysis by gas chromatography-mass spectrometry (GC-MS)}

Before GC-MS analysis, aliquots of each dried extract (nearly $20 \mathrm{mg}$ each) and an accurate amount of internal standard (hexadecane, $0.8 \mathrm{mg}$ ) were dissolved in $1100 \mu \mathrm{L}$ of dichloromethane. High pressure extracts were, prior to the injection, filtered through a syringe filter $(0.2 \mu \mathrm{m}$ Teflon filter).

The extracts were analysed by GC-MS following previously described methodologies ${ }^{5,28,29}$ on a GCMS-QP2010 Ultra (Shimadzu, Kyoto, Japan) equipment, equipped with a DB-1 J\&W (Agilent, Santa Clara, CA, United States) capillary column (30 $\mathrm{m} \times 0.32 \mathrm{~mm}$ inner diameter, $0.25 \mu \mathrm{m}$ film thickness). The chromatographic conditions were as follows: initial temperature, $80{ }^{\circ} \mathrm{C}$ for $5 \mathrm{~min}$; temperature gradient, $52{ }^{\circ} \mathrm{C} \mathrm{min}^{-1}$; final temperature $285{ }^{\circ} \mathrm{C}$ for $8 \mathrm{~min}$; injector temperature, $250{ }^{\circ} \mathrm{C}$; transfer-line temperature, $290{ }^{\circ} \mathrm{C}$; split ratio, $1: 40$.

The identification of compounds was carried out through the comparison of their mass spectra fragmentation profile with library (Wiley 275 and U.S National Institute of Science and Technology (NIST14)), their characteristic retention times obtained under the described experimental conditions ${ }^{5}$ and by comparing their mass spectra fragmentation profiles with published data ${ }^{9,10,28}$ or by injection of standards.

For semi-quantitative analysis and to determine the response factor for diterpenes, GC-MS was calibrated with phytol, relative to hexadecane. The respective response factor was calculated as an average of six GC-MS runs. Three aliquots of each extract were injected in duplicate, and the results correspond to the average of the concordant values obtained (less than $5 \%$ variation between injections of the same aliquot). The compound contents were expressed as milligram per gram of extract ( $\mathrm{mg} \mathrm{g}^{-1}$ of extract) and as milligram per kilogram of $\mathrm{dw}$ of macroalgae $\left(\mathrm{mg} \mathrm{kg}^{-1} \mathrm{dw}\right)$.

\subsection{Scanning electron microscopy (SEM) analysis}

SEM micrographs were obtained by a Hitachi SU-70 microscope operating at $4 \mathrm{kV}$. Dried samples (initial lyophilized macroalgae, and macroalgae after Soxhlet and high-pressure extractions) were placed in an aluminium support with double sided carbon tape and deposited with a carbon coating before SEM analysis.

\subsection{In chemico and in vitro biological activities evaluation}

2.6.1 Antioxidant activity evaluation. The antioxidant activity of $B$. bifurcata extracts was measured through the 2,2diphenyl-1-picrylhydrazyl radical ( $\left.\mathrm{DPPH}^{\circ}\right)$ assay, which evaluates the hydrogen-donating or radical scavenging ability of extracts, following a procedure reported before. ${ }^{5}$

The dry extracts were previously dissolved in methanol $(4 \mathrm{mg}$ $\left.\mathrm{mL}^{-1}\right)$. Sample aliquots $(0.5 \mathrm{~mL})$ were mixed with $0.125 \mathrm{~mL}$ of
$\mathrm{DPPH}^{\bullet}(0.8 \mathrm{mM}$ in methanol) and $1.375 \mathrm{~mL}$ of methanol. The ranges of final concentrations were $50-1000 \mu \mathrm{g} \mathrm{mL}{ }^{-1}$ for Soxhlet extract and $20-100 \mu \mathrm{g} \mathrm{mL}{ }^{-1}$ for high pressure extracts. Mixtures were homogenized in vortex. After $30 \mathrm{~min}$ of incubation in the dark, at room temperature, the absorbance was read at $517 \mathrm{~nm}$, against a blank, using a Shimadzu UV-1800 spectrophotometer (Kyoto, Japan). Duplicate measurements of each extract were carried out and each absorbance was compared to a control without extract.

The antioxidant activity was expressed as a percentage of DPPH radical reduction, using the following eqn (2):

$\%$ DPPH reduction $=\frac{(\mathrm{Abs}(\text { control })-\text { Abs }(\text { sample }))}{\operatorname{Abs}(\text { control })} \times 100$

The inhibitory concentration of the extract required to decrease the initial DPPH radical concentration by $50 \%\left(\mathrm{IC}_{50}\right)$ was determined from the graph of DPPH reduction percentage in function of extracts concentration. The $\mathrm{IC}_{50}$ values were expressed in $\mu \mathrm{g} \mathrm{mL}^{-1}$.

2.6.2 Antibacterial activity evaluation. The antibacterial activity of $B$. bifurcata extracts was evaluated against Grampositive bacteria Staphylococcus aureus ATCC $® 43300$, through minimal inhibitory concentration (MIC) and minimal bactericidal concentration (MBC) determinations and, also, through a synergistic assay by conjugation of the extract with antibiotics. Antibacterial activity assays were performed according to Clinical and Laboratory Standard Institute (CLSI) guidelines ${ }^{\mathbf{3 0}}$ and following the procedure described in a previous work by Santos et al., ${ }^{5}$ with some modifications. Briefly, S. aureus cells in exponential phase were suspended in Mueller-Hinton Broth (MHB; Liofilchem, Italy) to obtain a concentration of $5 \times 10^{5} \mathrm{cfu}$ $\mathrm{mL}^{-1}$ and $B$. bifurcata extracts, obtained from high pressure and Soxhlet extractions, were dissolved in dimethyl sulfoxide (DMSO; Applichem, Germany) to a final stock concentration of $50 \mathrm{mg} \mathrm{mL}^{-1}$. The method used was microbroth dilution, using a range of concentration from 8 to $2048 \mu \mathrm{g} \mathrm{mL} \mathrm{mL}^{-1}$, in a 96-well plate (TPP, Switzerland). ${ }^{31}$ MIC was assessed qualitatively by adding Resazurin sodium salt $0.1 \mathrm{mg} \mathrm{mL}^{-1}$ (Sigma-Aldrich, USA) in each well, after $24 \mathrm{~h}$ of incubation at $37^{\circ} \mathrm{C}$, according to the protocol described by Riss et $a l .{ }^{32}$ with slight adaptations. Resazurin allows MIC visualization at naked eye where the originally blue colour does not turn to pink and fluorescent colour, product of viable cells metabolism. Experiments were performed three times and each one with triplicates $(n=9)$.

MBC, defined as the lowest concentration of the extract that results in killing $99.9 \%$ of bacterial cells, was determined by subculturing the corresponding MIC onto agar plates. In this assay, MIC and concentrations above were plated on MuellerHinton Agar (MHA; Liofilchem, Italy), using the spreading technique. The lowest concentration without visible growth corresponded with the MBC. Experiments were performed three times and each one with duplicates $(n=6)$.

The synergistic assay was performed following the protocol described above, according to Santos et al. ${ }^{5}$ B. bifurcata high pressure extract was conjugated with the antibiotics rifampicin (Rif; Duchefa Biochemie, Alfagene), tetracycline (Tetra; Duchefa 
Biochemie, Alfagene), gentamicin (Gent; Duchefa Biochemie, Alfagene) and ampicillin (Amp; Duchefa Biochemie, Alfagene) in a concentration range from 2 to $256 \mu \mathrm{g} \mathrm{mL}{ }^{-1}$. Experiments were performed three times and each one with triplicates $(n=$ 9). Factorial inhibitory concentration index (FICI) was calculated to classify interaction between $B$. bifurcata high pressure extract and antibiotics. ${ }^{33}$ Each of the combinations was calculated according to the following eqn (3):

$$
\mathrm{FICI}=\frac{\text { MIC }(\text { antibiotic }+ \text { extract })}{\text { MIC }(\text { antibiotic })}
$$

Results were interpreted as follows: FICI $\leq 0.5$ synergistic $(\mathrm{S})$, $0.5<$ FICI $<1$ partially synergistic (PS), FICI $=1$ additive (ADD), 1 $<$ FICI $\leq 4$ indifferent (I) and FICI $>4$ antagonistic (ANT).

\section{Results and discussion}

\subsection{Lipophilic fraction obtained by soxhlet extraction}

The lipophilic extract of wild B. bifurcata obtained by Soxhlet extraction presented an EY of $9.4 \pm 0.1 \%$ (w/w) which was about three-fold higher than the Soxhlet EY obtained previously for $B$. bifurcata also from Portugal. ${ }^{5}$ Additionally, the EY observed was considerably higher than those previously reported for other Phaeophyta species. ${ }^{28,34}$ A detailed study of B. bifurcata Soxhlet extracts composition was performed by GC-MS analysis (Table 1), according to a previously established methodology. ${ }^{5}$

B. bifurcata has already been studied due to its variety of diterpenes. ${ }^{2,6-12}$ However, only a single detailed study of its lipophilic fraction was performed by GC-MS analysis, in which other compounds were identified and quantified, namely sterols, fatty acids, long-chain aliphatic alcohols, monoglycerides, among others. ${ }^{5}$

Several diterpenes were identified in B. bifurcata Soxhlet extract, namely neophytadiene, phytol, trans-geranylgeraniol, 6,7,9,10,11,12,14,15-tetrahydrophytol, 6-hydroxy-13-oxo$7,7^{\prime}, 10,11$-didehydrophytol, eleganolone, and 1-acetyl-10,13dioxo-6,7,11,11',14,15-tridehydrophytol. Some of these linear compounds were previously detected in B. bifurcata collected at different geographical points, such as France, ${ }^{\mathbf{9}, 11,35}$ Morocco $^{\mathbf{1 0}}$ and Spain. ${ }^{36}$ Phytol and neophytadiene were also reported before as constituents of this macroalga from Portugal. ${ }^{5}$ trans-
Geranylgeraniol was already identified as B. bifurcata constituent from Morocco ${ }^{\mathbf{8 , 3 7}}$ and Brittany.,37

The diterpenes in the studied extracts were identified by comparing the mass spectra fragmentation profile with libraries (Wiley 275 and U.S. National Institute of Science and Technology (NIST14)), their characteristic retention times obtained under the described experimental conditions ${ }^{5}$ and literature data. ${ }^{9,10,28}$

Diterpenes accounted for $6395 \mathrm{mg} \mathrm{kg} \mathrm{kg}^{-1} \mathrm{dw}$ of B. bifurcata. Eleganolone and 6-hydroxy-13-oxo-7,7',10,11-didehydrophytol were the major components of this family, accounting for $6180 \mathrm{mg} \mathrm{kg}^{-1} \mathrm{dw}$ and $144 \mathrm{mg} \mathrm{kg}^{-1} \mathrm{dw}$, respectively. 1-Acetyl10,13-dioxo-6,7,11,11',14,15-tridehydrophytol and neophytadiene were also present in considerable amounts.

These linear diterpenes have been the focus of interest of several studies, since they are relatively rare in nature. ${ }^{2,15}$ In addition, they have been associated with several biological activities, such as antioxidant, antimicrobial and antiinflammatory properties. ${ }^{5,38}$

In order to obtain these extracts without the use of hazardous solvents and using a more sustainable approach we decided to study their extraction with ethanol : water under HPE.

\subsection{Preliminary high-pressure extractions}

Preliminary HPE experiments were performed considering two independent variables, namely the extraction pressure $(600,300$ and $0.1 \mathrm{MPa}$ ) and the ethanol : water ratio (80:20 and $60: 40)$. These experiments were carried out to choose the experimental design variables and their ranges of values, and thus the type of experimental design. As shown in Table 2, the differences observed in the EY and DC $\left(\mathrm{mg} \mathrm{g}^{-1}\right.$ of extract and $\mathrm{mg} \mathrm{kg}^{-1} \mathrm{dw}$ ) values of the preliminary experiments indicated that these factors have possible significant effects on the results.

HPE extracts presented quite different EY values, accounting $6.9 \%(\mathrm{w} / \mathrm{w})$ at $600 \mathrm{MPa}$ and $80 \%$ ethanol and $11.9 \%(\mathrm{w} / \mathrm{w})$ at $300 \mathrm{MPa}$ and $60 \%$ ethanol. These values are also different from that obtained with Soxhlet extraction $(9.4 \%(\mathrm{w} / \mathrm{w}))$. The experiment 3 (Table 2), performed at atmospheric pressure and $80 \%$ ethanol, showed an EY of $8.4 \%(w / w)$, which is in the range of those obtained at higher pressure and lower than that obtained with Soxhlet extraction.

Table 1 Diterpenes identified in B. bifurcata Soxhlet extract expressed in $\mathrm{mg} \mathrm{g}^{-1}$ of extract and in $\mathrm{mg} \mathrm{kg}^{-1} \mathrm{dw}$

\begin{tabular}{|c|c|c|c|}
\hline Compound & $\mathrm{mg} \mathrm{g}^{-1}$ of extract ${ }^{a}$ & $\mathrm{mg} \mathrm{kg}{ }^{-1} \mathrm{dw}^{a}$ & $\operatorname{Rt}(\min )$ \\
\hline Neophytadiene & 0.13 & 15 & 26.7 \\
\hline Phytol & 0.03 & 4 & 32.3 \\
\hline $6,7,9,10,11,12,14,15$-Tetradehydrophytol & 0.07 & 9 & 34.4 \\
\hline 6-Hydroxy-13-oxo-7, $7^{\prime}, 10,11$-didehydrophytol & 1.12 & 144 & 36.3 \\
\hline Eleganolone & 48.44 & 6180 & 38.0 \\
\hline
\end{tabular}

${ }^{a}$ Results correspond to the average value estimated from the injection of three aliquots analysed in duplicate (standard deviation $<5$ ). 
Table 2 Preliminary experiments extraction yield (EY) and diterpenes content (DC)

\begin{tabular}{|c|c|c|c|c|c|}
\hline Preliminary experiment no. & \multicolumn{2}{|c|}{ Independent variables } & \multicolumn{3}{|c|}{ Response variables $^{a}$} \\
\hline 2 & 300 & 60 & 11.9 & 333.5 & 43527 \\
\hline 3 & 0.1 & 80 & 8.4 & 4299 & 39679 \\
\hline
\end{tabular}

${ }^{a}$ Results correspond to the average value estimated from the injection of three aliquots analysed in duplicate (standard deviation $<5 \%$ ).

All the preliminary extractions showed total amounts of diterpenes (31 557 and $43527 \mathrm{mg} \mathrm{kg}^{-1} \mathrm{dw}$ ) higher than that obtained with Soxhlet extraction (6394 $\mathrm{mg} \mathrm{kg}^{-1} \mathrm{dw}$ ). The experiments with $80 \%$ ethanol ( 1 and 3 ) showed the highest DC values, suggesting that the ethanol percentage could have a high effect on the diterpenes yield. Comparing the experiments at different pressures (1 and 3), with the same ethanol percentage, the DC at atmospheric pressure was slightly higher than that obtained at $600 \mathrm{MPa}$. However, the standard deviation associated to experiment 3 was considerably high and therefore the differences may not be statistically significant.

When a lower ethanol percentage $(60 \%)$ was used with a pressure of $300 \mathrm{MPa}$, higher EY and lower DC were achieved, which could mean that under these HPE conditions, the extraction of other compounds, such as polysaccharides, can be favored in the detriment of diterpenes extraction.

With the preliminary experiments, it was verified that HPE could be more selective to the diterpenic compounds, than the conventional extraction methodology. Therefore, pressure and ethanol percentage were chosen as variables to optimize. In addition, and taking into account the high number of studies showing a high effect of extraction time on the EY of target compounds, ${ }^{27,39,40}$ time was selected as the third variable for the experimental design. EY and DC (expressed as $\mathrm{mg} \mathrm{g}^{-1}$ of extract and $\mathrm{mg} \mathrm{kg}^{-1} \mathrm{dw}$ ) were selected as responses to optimize.

A pressure range between 0.1 and $600 \mathrm{MPa}$ was selected, due to the highest DC observed for the preliminary experiments 1 (600 MPa) and $3(0.1 \mathrm{MPa})$. Actually, $600 \mathrm{MPa}$ correspond to the maximum value of pressure enabled by the equipment, so the full possible range was considered in order to enhance the maximum rupture of macroalga cell walls. ${ }^{27}$

In the same way, DC values were different at diverse mixture concentration. Therefore, the effect of this factor was evaluated in an extended range, namely between $40 \%$ and $80 \%$ of ethanol.

Finally, extraction time was selected to be 5-30 min, which has been in the range of most of the optimal extraction times reported in several studies. ${ }^{27,39,40}$

\subsection{Analysis of the designed HPE experiments}

HPE of diterpenes from $B$. bifurcata was optimized by response surface methodology using a Box-Behnken design. EY and DC expressed in $\mathrm{mg} \mathrm{g}^{-1}$ of extract and in $\mathrm{mg} \mathrm{kg}^{-1} \mathrm{dw}$ of $B$. bifurcata extracts are shown in Table 3 . The predicted values, within the limits of the experimental factors, are also listed in Table 3.
From a qualitative point of view and similarly to the observed in preliminary experiments, the lipophilic composition of HPE extracts was very similar to the Soxhlet extract.

3.3.1 Model fitting for experimental design. A BoxBehnken design was formulated to develop an empirical model for each measured response (namely, EY and DC, expressed as $\mathrm{mg} \mathrm{g}^{-1}$ of extract and $\mathrm{mg} \mathrm{kg}^{-1} \mathrm{dw}$ ) thereby evaluating the effect of the interaction of three independent variables (extraction pressure $\left(X_{1}\right)$, ethanol percentage $\left(X_{2}\right)$, and extraction time $\left.\left(X_{3}\right)\right)$ in the extraction of these bioactive compounds. The second order quadratic models were expressed as a function of the independent variables.

The results of 15 experiments including three replicates at the centre point were analysed, using the response surface methodology. Linear and quadratic effects of the three variables studied as well as their interactions were evaluated for regression coefficients.

3.3.2 Independent variables effect on extraction yield. Only the independent variables ethanol percentage $\left(X_{2}\right)$ and time of extraction $\left(X_{3}\right)$ had a significant effect $(P<0.05)$ on EY (Table $1 \mathrm{~S} \dagger$ ). The EY of these 15 experiments ranged from 3.5 to $12.6 \%(\mathrm{w} / \mathrm{w})$, and this last value was obtained under the following conditions: $600 \mathrm{MPa}\left(X_{1}\right), 60 \%\left(X_{2}\right)$ and $30 \mathrm{~min}\left(X_{3}\right)$. Additionally, the percentage of ethanol was the most significant effect observed, presenting a $F$ value of $19.96\left(X_{2}\right)$, and extraction time was the second most significant factor exhibiting $F$ value of $7.53\left(X_{3}\right)$.

The main effects of independent variables on the measured responses can be observed through the interpretation of the $2 \mathrm{D}$ contour and 3D surface response plots (Fig. 1). The increase of extraction time and the decrease of ethanol percentage led to an increase of the extraction yield, which is also verified in the positive and negative values of the $\beta$-coefficient value (for coded variables) of the linear term (Table $1 \mathrm{~S} \dagger$ ), respectively. This negative effect of the ethanol percentage could be related to the co-extraction of other components, namely polysaccharides, which are quite abundant in macroalgae, and their extraction may occur with high water contents on the extraction solvent mixture.

Extraction time also had a significant effect on the EY. As example, the yield increased from $3.5 \%(\mathrm{w} / \mathrm{w})$ at $300 \mathrm{MPa}, 80 \%$ ethanol and $5 \mathrm{~min}$ to $9.6 \%(\mathrm{w} / \mathrm{w})$ at $300 \mathrm{MPa}, 80 \%$ ethanol and $30 \mathrm{~min}$, which is a variation of $64 \%$. As HPE is known to be a faster methodology than other extraction methods, ${ }^{19}$ the extraction time only has to be long enough to ensure the contact 
Table 3 Box-Behnken matrix and experimental and predicted values of the response variables for the HPE of $B$. bifurcata

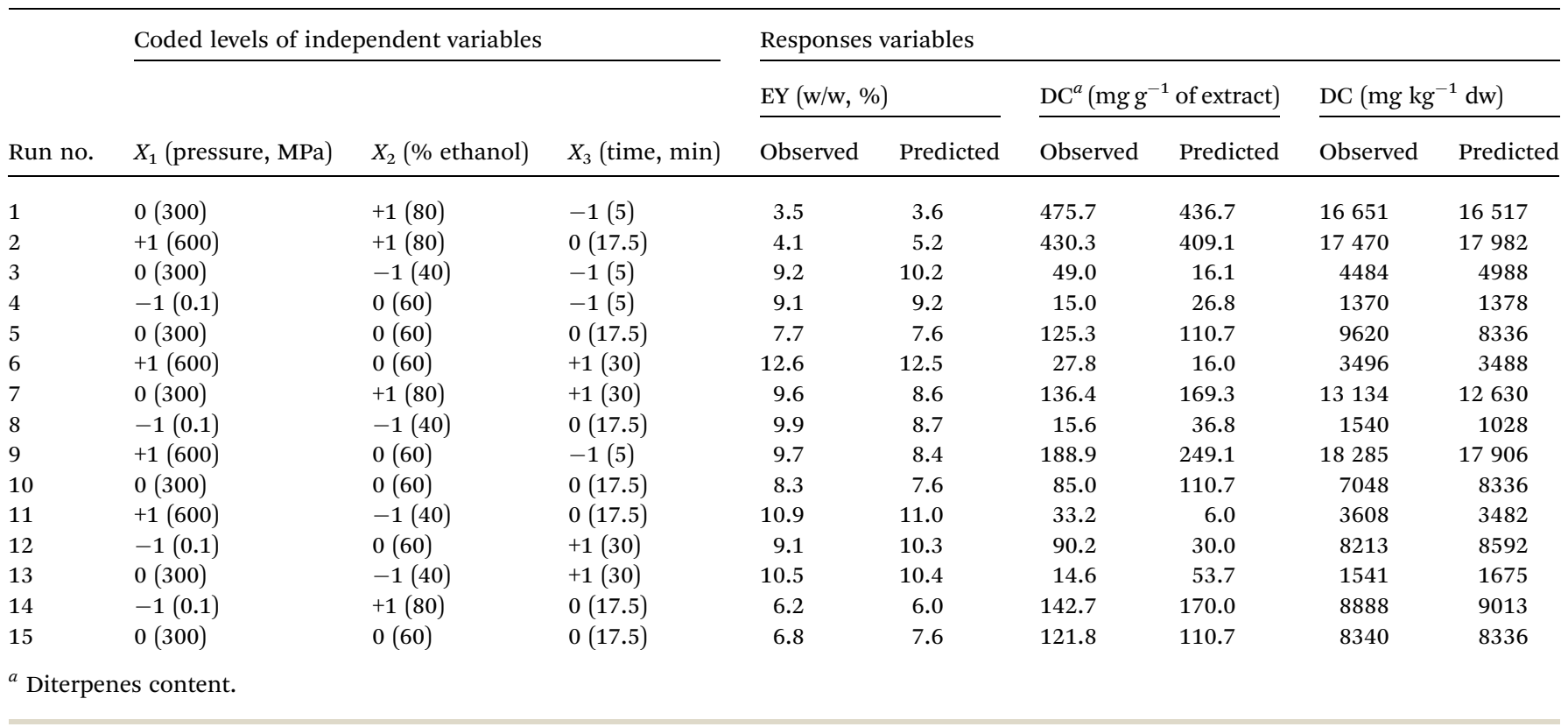

between the compounds and the solvent. ${ }^{40}$ Notwithstanding, a higher amount of extractives is expected when increasing the extraction time.

No significant effect was observed for pressure $(P>0.05)$ (Fig. 1a and b). However, the maximum EY $(12.6 \%(w / w))$ was obtained at $600 \mathrm{MPa}$, corresponding to an increase of $28 \%$ compared to the yield obtained with the same conditions at atmospheric pressure $(9.1 \%(\mathrm{w} / \mathrm{w}))$.

According to the model, the EY was maximized at $600 \mathrm{MPa}$, $40 \%$ ethanol and an extraction time of $30 \mathrm{~min}$, corresponding to a predicted value of $13.4 \%(\mathrm{w} / \mathrm{w})$. A $R^{2}$ of 0.894 was obtained, which means that $10.6 \%$ of total variations are not explained by the model. However, the $P$-value for the lack-of-fit was 0.17 , which shows that the model developed can represent well the results observed. ${ }^{27,41}$

3.3.3 Independent variables effect on diterpenes content ( $\mathbf{m g ~ g}^{-1}$ of extract). All linear effects $\left(X_{1}, X_{2}\right.$ and $\left.X_{3}\right)$ showed to significantly affect $(P<0.05)$ the DC, expressed in $\mathrm{mg} \mathrm{g}^{-1}$ of extract. Additionally, the interaction between ethanol percentage and extraction time $\left(X_{2} X_{3}\right)$ shows also a significant effect $(P<0.05)$ (Table $2 \mathrm{~S} \dagger)$. All the quadratic effects showed to not affect significantly the DC.

Higher ethanol percentages and/or higher extraction pressures led to higher DC ( $\mathrm{mg} \mathrm{g}^{-1}$ of extract), as can be seen in
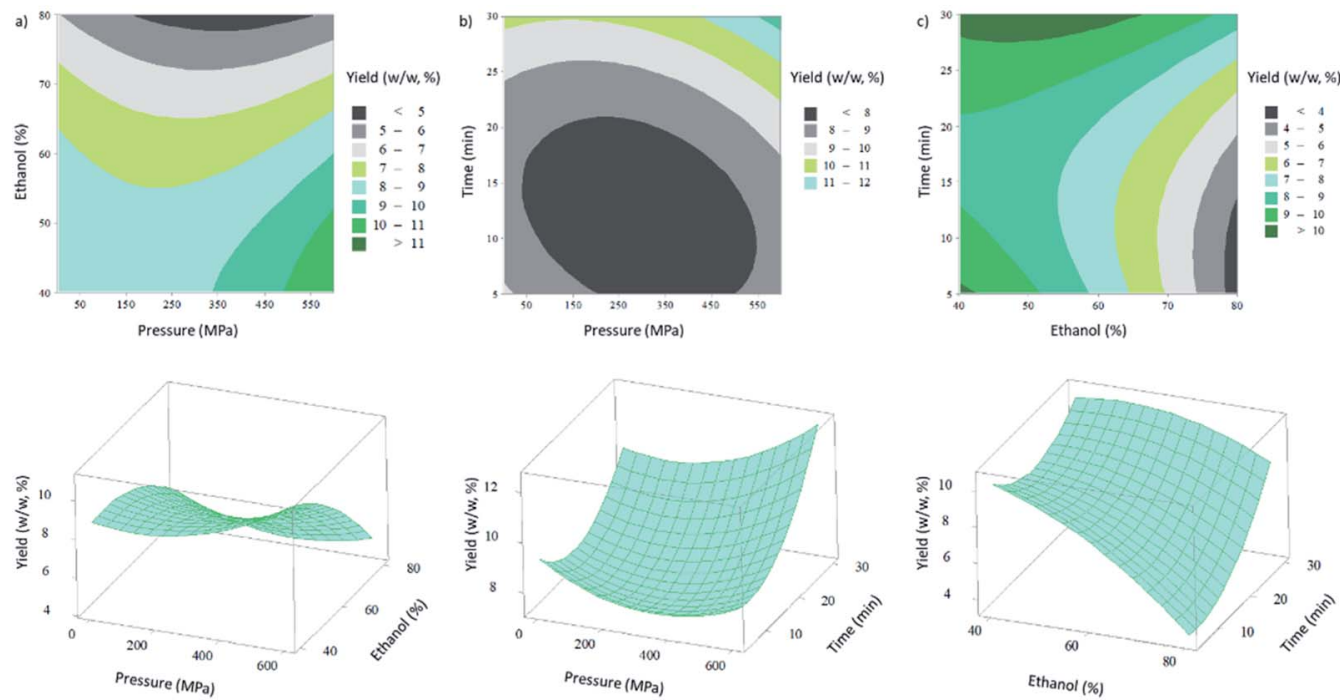

Fig. 1 Contour and response surface plots of extraction yield (w/w, \%) as a function of (a) ethanol percentage (\%) and pressure (MPa) (time $=17.5$ min); (b) time ( $\mathrm{min}$ ) and pressure (MPa) (ethanol =60\%); (c) time (min) and ethanol percentage (\%) (pressure $=300 \mathrm{MPa})$. 
contour and surface response plots (Fig. 2), through the positive $\beta$-coefficients values (for coded variables) of the linear terms ( $X_{1}$ and $X_{2}$ ).

In general, an increase in extraction pressure resulted in an increase on DC. When the pressure changed from 0.1 MPa to $600 \mathrm{MPa}$, maintaining the remaining extraction conditions $\left(X_{2}\right.$ : $80 \%$ and $X_{3}: 17.5 \mathrm{~min}$ ), the DC increased from 142.7 to $430.3 \mathrm{mg}$ $\mathrm{g}^{-1}$ of extract $(\sim 67 \%)$. This positive effect of pressure was expected, since at higher pressures the cell structures and membranes are destroyed, which increases mass transfer of solvents into raw materials, as well as of the soluble constituents into the solvents. ${ }^{19}$ Concerning the effect of extraction time, the highest DC was obtained for the lower extraction time ( $5 \mathrm{~min}$ ), which is also reflected in the negative value of the $\beta$ coefficient value (for coded variables) of the linear term. At $600 \mathrm{MPa}$ and $60 \%$ of ethanol, the extractions carried out during 5 and 30 minutes, resulted in DC of 188.9 and $27.8 \mathrm{mg} \mathrm{g}^{-1}$ of extract, respectively. This means that the longer the extraction time, the lower the DC.

A hypothesis to explain the negative effect of extraction time is based on a higher abundance of co-extracted compounds, such as, polysaccharides, and a possible adsorption of diterpenes in the macromolecules. In fact, brown macroalgae are known for their high content in polysaccharides. ${ }^{42,43}$ Before GCMS analysis, several steps are performed, such as filtration, where losses can result in the reduction of co-extracted compounds. Upon elimination, the polysaccharides may consequently retain part of the diterpenes, which results in a decrease in this response.

The maximum of DC (475.7 $\mathrm{mg} \mathrm{g}^{-1}$ of extract) was achieved at $300 \mathrm{MPa}$, the value of extraction pressure, with the lowest extraction time $(5 \mathrm{~min})$ and with the highest percentage of ethanol (80\%). However, at $300 \mathrm{MPa}$ an extraction time of $30 \mathrm{~min}$ and with a percentage of ethanol of $40 \%$, the minimum amount of diterpenes per $g$ of extract (14.6) was extracted. This means that the ethanol percentage and the extraction time were the most significant effects, which is in accordance to the $F$ values of their linear effects (44.60 and 8.19, respectively) (Table 2S†).

According to the model, the maximum predicted DC (593.5 $\mathrm{mg} \mathrm{g}^{-1}$ of extract) could be obtained with the following HPE conditions: extraction pressure $\left(X_{1}\right), 600 \mathrm{MPa}$; ethanol percentage $\left(X_{2}\right), 80 \%$; and extraction time $\left(X_{3}\right), 5 \mathrm{~min}$.

The $R^{2}$ value (Table $2 S \dagger$ ) of this model was 0.943 , which represents a good correlation between the observed and predicted values, where more than $94 \%$ of responses variability are explained by the model. Furthermore, the $P$-value for the lackof-fit non-significant (0.09) suggests once more that the developed model can represent the observed results.

3.3.4 Independent variables effect on diterpenes content ( $\mathbf{m g ~ k \mathbf { ~ k g } ^ { - 1 }} \mathbf{d w}$ ). Regarding DC expressed as $\mathrm{mg} \mathrm{kg}^{-1} \mathrm{dw}$, with the exception of ethanol : time interaction term $\left(X_{2} X_{3}\right)$, all the linear and interaction effects showed to have significant effect $(P$-value $<0.05$ ) (Table 3S†). The 2D contour and 3D surface response plots in Fig. 3 show that DC $\left(\mathrm{mg} \mathrm{kg}^{-1} \mathrm{dw}\right)$ increased with increased ethanol percentage and extraction pressure. In fact, the positive $\beta$-coefficients values (for coded variables) of the corresponding linear terms (Table $3 S^{\dagger} \dagger$ ) are in agreement with this effect. However, and similarly with the observed for the DC in a basis of extract, the effect of extraction time was opposite, obtaining higher diterpenes amount per $\mathrm{kg}$ of $\mathrm{dw}$ when the extraction has a short length. As expected, the linear effect of each variable in this response was quite similar to those of the previous response.

In this measured response, the effect of extraction pressure was more evident when compared with the other models. The two HPE performed with $60 \%$ of ethanol, for $5 \mathrm{~min}$, at different values of pressure ( 0.1 and $600 \mathrm{MPa}$ ), resulted in a minimum (1370 $\mathrm{mg} \mathrm{kg}^{-1} \mathrm{dw}$ ) and maximum (18 $285 \mathrm{mg} \mathrm{kg}^{-1} \mathrm{dw}$ ) DC, respectively. Thus, the highest extraction pressure ensured a higher DC. In fact, when the compression level applied exceeds the deformation limit of the cells, can lead to formation
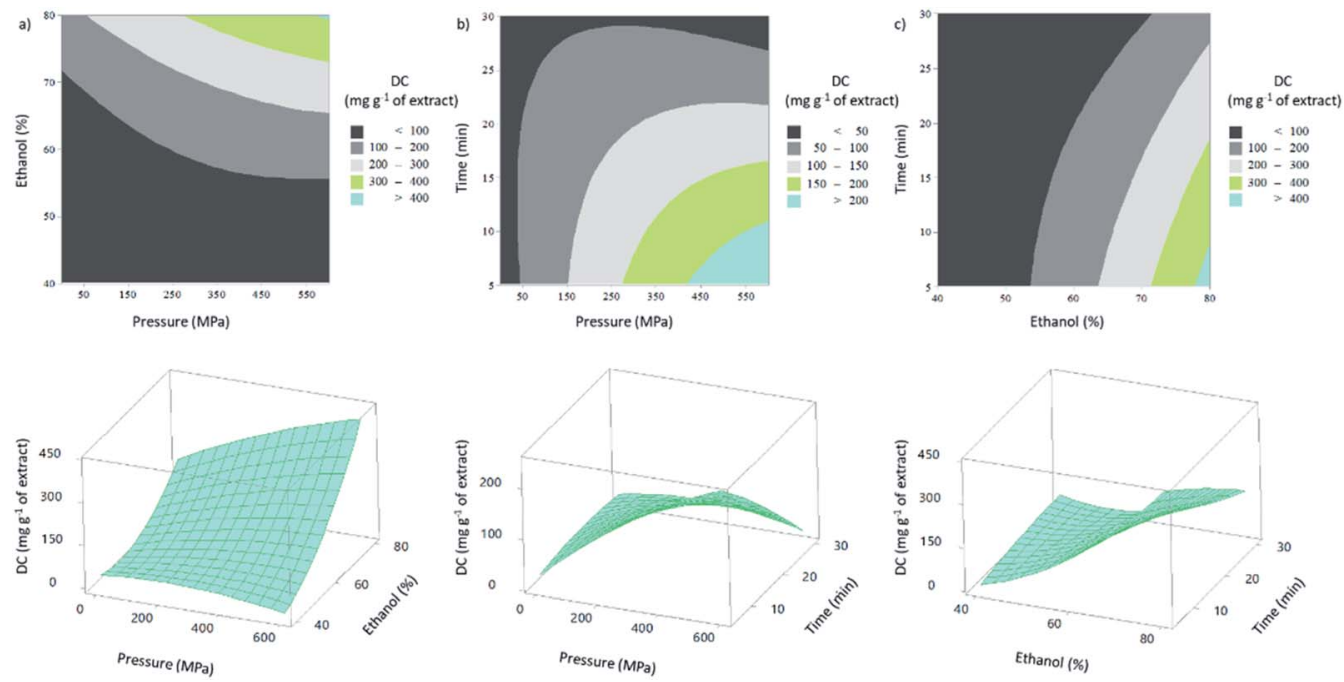

Fig. 2 Contour and surface response plots of diterpenes content ( $\mathrm{mg} \mathrm{g}^{-1}$ of extract), as a function of (a) percentage of ethanol (\%) and pressure $(\mathrm{MPa})($ time = 17.5); (b) time ( $\mathrm{min})$ and pressure $(\mathrm{MPa})($ ethanol $=60 \%)$; (c) time (min) and percentage of ethanol (\%) (pressure $=300 \mathrm{MPa})$. 

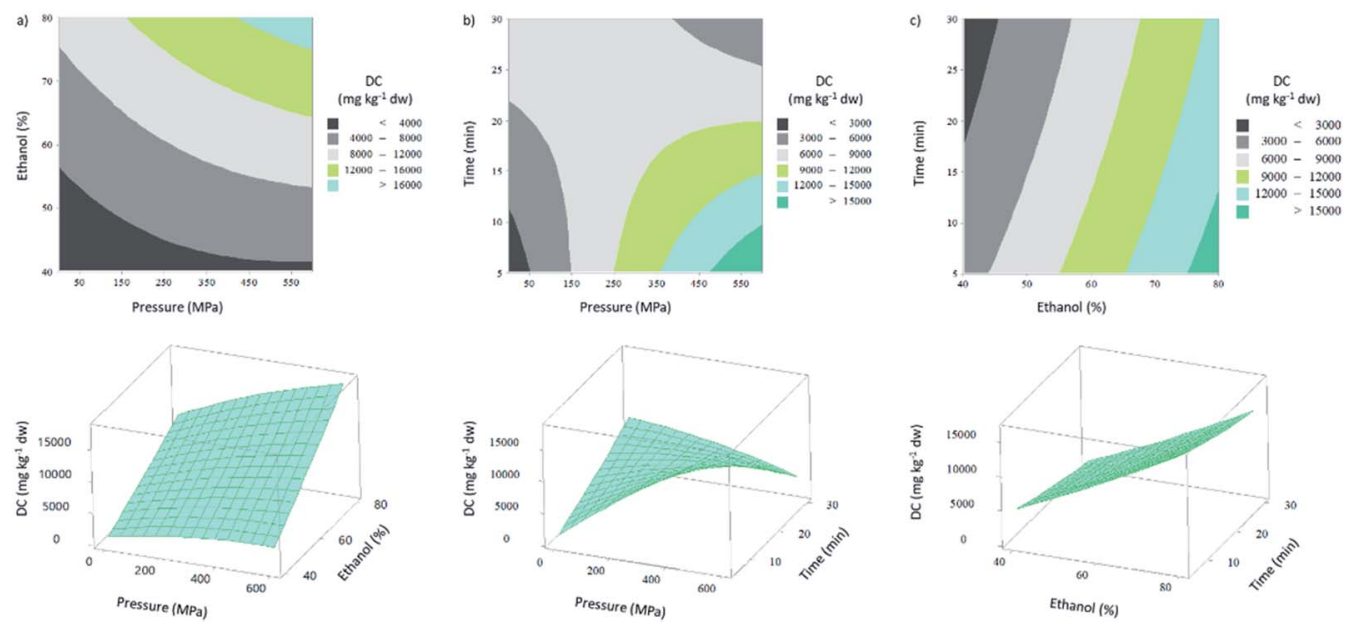

Fig. 3 Contour and surface response plots of diterpenes content ( $\mathrm{mg} \mathrm{kg}^{-1} \mathrm{dw}$ ), as a function of (a) percentage of ethanol (\%) and pressure (MPa) $($ time = 17.5); (b) time $(\mathrm{min})$ and pressure $(\mathrm{MPa})$ (ethanol =60\%); (c) time (min) and percentage of ethanol (\%) (pressure = $300 \mathrm{MPa})$.

of cracks, ${ }^{19}$ resulting in more solvent inside the cells and consequently more compounds permeate the damaged cell membrane. ${ }^{40}$

Notwithstanding, the most important effect to achieve higher amounts of diterpenes was the ethanol percentage, which had a $F$ value of 269.12 (linear effect), represented in Table 3S. $\dagger$ DC $\left(\mathrm{mg} \mathrm{kg}^{-1} \mathrm{dw}\right)$ increased $79 \%$, when the ethanol percentage was changed from $40 \%\left(3608 \mathrm{mg} \mathrm{kg}^{-1} \mathrm{dw}\right)$ to $80 \%$ (17 $470 \mathrm{mg} \mathrm{kg}^{-1} \mathrm{dw}$ ).

Pressure : time interaction also had a significant effect $(F$ value of 124.54) (Table $3 \mathrm{~S}^{\dagger}$ ) on the DC in a dw basis. According to the model, the maximum predicted DC $\left(25625.2 \mathrm{mg} \mathrm{kg}^{-1}\right.$ $\mathrm{dw}$ ) is achieved at $X_{1}: 600 \mathrm{MPa} ; X_{2}: 80 \%$; and $X_{3}: 5 \mathrm{~min}$. At these extraction conditions, there is a large pressure differential between the intra- and extracellular medium, which will lead to a rapid permeation of the compounds obtaining the equilibrium in a shorter time. ${ }^{40}$

The $R^{2}$ and $R_{\mathrm{adj}}{ }^{2}$ of the predicted model were 0.990 and 0.973 , respectively, which did not differ significantly. In agreement with these statistical parameters, the $P$-value of lack-of-fit was $0.84(P$-value $>0.05)$ (Table $3 S \dagger)$, which is another evidence that the model equation for DC $\left(\mathrm{mg} \mathrm{kg}^{-1} \mathrm{dw}\right)$ was adequate to predict the respective values under any sets of combination within the range of experimental values. Additionally, only $27 \%$ of samples showed a variation between values higher than $10 \%$ (Table 3).

\subsection{Optimization of high-pressure extraction conditions}

The optimization of HPE of diterpenes from B. bifurcata was performed in order to maximize the DC (expressed as $\mathrm{mg} \mathrm{g}^{-1}$ of extract and $\mathrm{mg} \mathrm{kg}^{-1} \mathrm{dw}$ ) and not $\mathrm{EY}$, because an increase in the EY might mean an increase of co-extracted polysaccharides. The optimized extraction pressure, ethanol percentage and extraction time were $600 \mathrm{MPa}, 80 \%$ and $5 \mathrm{~min}$, respectively. According to the models, the predicted results in extract and dw basis under these conditions were $593.5 \mathrm{mg} \mathrm{g}^{-1}$ of extract and $25625 \mathrm{mg} \mathrm{kg}^{-1} \mathrm{dw}$, respectively. The experimental results achieved at this point were $612.2 \pm 10.6 \mathrm{mg} \mathrm{g}^{-1}$ of extract and $38954 \pm 633 \mathrm{mg} \mathrm{kg}^{-1} \mathrm{dw}$ (Table 4). The difference between the predicted and experimental values was satisfactory, being the variation lower than $5 \%$ for DC ( $\mathrm{mg} \mathrm{g}^{-1}$ of extract), which validates the respective model.

\subsection{Comparative perspective between HPE at optimal conditions and conventional extraction}

3.5.1 Extraction yield and diterpenes content. As mentioned before, the optimal HPE conditions were determined to maximize the DC, in both extract and dw basis. Actually, the optimal conditions determined for EY were different $\left(X_{1}: 600 \mathrm{MPa} ; X_{2}: 40 \% ; X_{3}: 30 \mathrm{~min}\right)$. For this reason, the experimental yield obtained at the optimal HPE conditions (6.9 $\pm 0.6 \%(\mathrm{w} / \mathrm{w}))$ was lower than the Soxhlet EY $(9.4 \pm 0.1 \%(\mathrm{w} / \mathrm{w}))$, as shown in Table 4.

Concerning the amount of diterpenes in the extract, HPE allowed obtaining $612.2 \pm 10.6 \mathrm{mg} \mathrm{g}^{-1}$ of extract, which is 12.2fold higher than conventional extraction $\left(50.1 \mathrm{mg} \mathrm{g}^{-1}\right.$ of extract). In the same way, the DC in a dw basis in HPE accounted for $38954 \pm 633 \mathrm{mg} \mathrm{kg}^{-1} \mathrm{dw}$, which is considerably higher (6.1-fold) than that obtained with Soxhlet extraction (6395 $\mathrm{mg} \mathrm{kg}^{-1} \mathrm{dw}$ ).

Table 4 Experimental values of extraction yield (EY) and diterpenes content (DC) obtained in B. bifurcata Soxhlet and optimized HPE extracts $^{a}$

\begin{tabular}{llll}
\hline & \multicolumn{2}{l}{ Responses variables } \\
\cline { 2 - 4 } Optimal conditions & $\mathrm{EY}(\mathrm{w} / \mathrm{w}, \%)$ & \multicolumn{1}{l}{$\begin{array}{l}\mathrm{DC} \\
\left(\mathrm{mg} \mathrm{g}^{-1} \text { of extract }\right)\end{array}$} & $\begin{array}{l}\mathrm{DC} \\
\left(\mathrm{mg} \mathrm{kg}^{-1} \mathrm{dw}\right)\end{array}$ \\
\hline Soxhlet extraction & $9.4 \pm 0.1$ & $50.1 \pm 13.2$ & $6394 \pm 767$ \\
HPE & $6.9 \pm 0.6$ & $612.2 \pm 10.6$ & $38954 \pm 633$
\end{tabular}

${ }^{a}$ HPE - high pressure extraction; dw - dry weight. 
3.5.2 SEM analysis. Once the optimal HPE conditions were achieved, and in order to verify the effect of this methodology on biomass structure, SEM analysis was performed. As mentioned before, the basis of this extraction methodology is the increase permeability of pressurized cells. ${ }^{19}$ At high pressure, the surface area increases since pores and gaps are formed in the cells structures (cellular membranes and organelles membranes), which facilitate the solvent entry on the cell. ${ }^{17,19}$

Macroalgae before (Fig. 4a) and after conventional (Fig. 4b) and HPE at optimal conditions (Fig. 4c) were analysed by SEM. The higher magnification images $(\times 2.5 \mathrm{k})$ showed the biggest differences at the cell surface level, between the three samples. The image of the initial macroalga shows a regular surface, whereas the image correspondent to macroalga after Soxhlet extraction present already some damages. Nonetheless, the most evident surface damages are present in the macroalga after HPE, where gaps can be observed in the cell structure.

The SEM images of these samples corroborated the results reported above, notably the higher amount of diterpenes extracted in HPE, since greater damage in the cell structure leads to a reduction of mass transfer resistance and, consequently, to a higher amount of compounds extracted.

3.5.3 Antioxidant activity evaluation. The antioxidant activity of $B$. bifurcata extracts, obtained by Soxhlet and HPE at optimal conditions was studied in chemico by the DPPH assay and the results expressed as $\mathrm{IC}_{50}$.

Previous antioxidant activity results of solid-liquid and Soxhlet $B$. bifurcata extract against $\mathrm{DPPH}^{\circ}$, reported for a wild sample collected from Peniche Coast Portugal $\left(345 \mu \mathrm{g} \mathrm{mL}^{-1}\right.$ (246.10-482.80) $)^{3}$ and for a sample from an integrated multitrophic aquaculture from Portugal $\left(366 \pm 10 \mu \mathrm{g} \mathrm{mL}{ }^{-1}\right){ }^{5}$ respectively, showed quite similar $\mathrm{IC}_{50}$ values. In the present work, the Soxhlet extract of B. bifurcata collected in the Portuguese north coast, presented an $\mathrm{IC}_{50}$ value of about $777 \pm 16 \mu \mathrm{g}$ $\mathrm{mL}^{-1}$, demonstrating a lower antioxidant activity than those reported before.
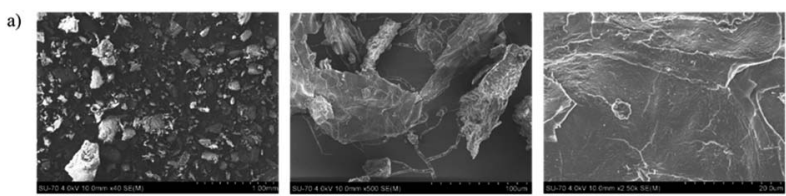

b)
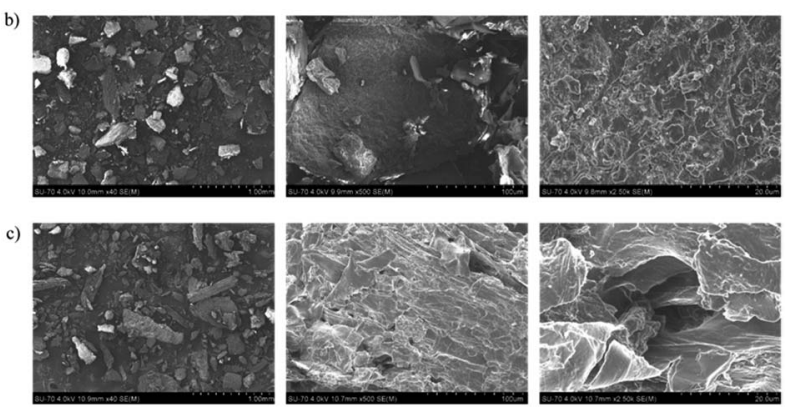

Fig. 4 SEM micrographs of macroalgae (a) before extraction, (b) after Soxhlet extraction and (c) after HPE for three different magnifications $(\times 40, \times 500$ and $\times 2.50 \mathrm{k})$
On the contrary, the antioxidant activity of B. bifurcata HPE extract obtained at the optimal conditions accounted for $28 \pm 2$ $\mu \mathrm{g} \mathrm{mL}{ }^{-1}$, which is a noticeably improved result compared to the Soxhlet extract obtained from the same macroalgae sample as well as from those previously reported in the literature. In addition, this $\mathrm{IC}_{50}$ value is in the same range of those reported in the literature for extracts rich in antioxidant compounds (e.g. phenolic compounds), ${ }^{44}$ which could emerge as a consequence of using $\mathrm{H}_{2} \mathrm{O}$ and ethanol as solvents, due to their higher polarity. Thus, these compounds not extracted with DCM can also contribute to an improvement of antioxidant activity. Although, these antioxidant activity results clearly demonstrate the potential of HPE in this context. This difference may be related with the higher abundance of diterpenes observed in HPE extract. In fact, diterpenes have been well recognized by their bioactivities including antioxidant. ${ }^{5}$

3.5.4 Antibacterial activity. The antibacterial activity of the B. bifurcata Soxhlet extract and HPE extract obtained at the optimal conditions were evaluated against Staphylococcus aureus ATCC ${ }^{\circledR} 43300$ and expressed as MIC and MBC values, which are present in Table 5. This strain has one of the highest antibiotic resistance, which is an important health concern, resulting in a demand for new therapeutic strategies to overcome it. ${ }^{5}$ Thus, in this study, the synergist effect of B. bifurcata HPE extract, obtained at optimal conditions, with four distinct antibiotics were evaluated, similarly to that studied previously for a dichloromethane $B$. bifurcata extract. ${ }^{5}$

The antibiotics used represent drug families of major clinical importance, such as aminoglycosides (Gent: gentamicin), tetracyclines (Tetra: tetracycline), macrocyclics (Rif: rifampicin), and $\beta$-lactams antibiotics, such as aminopenicillins (Amp: ampicillin). The results are expressed in MIC and FICI (Table 6). The antibacterial activity observed for the B. bifurcata Soxhlet extract $\left(\mathrm{MIC}=2048 \mu \mathrm{g} \mathrm{mL}{ }^{-1}\right.$ ) matched that obtained by Santos et $a .^{5}$

Whereas the activity of $B$. bifurcata HPE extract (MIC $=1024$ $\mu \mathrm{g} \mathrm{mL}^{-1}$ ) was 2-fold higher than that of Soxhlet extract. Furthermore, MBC determination showed that B. bifurcata HPE extract has bactericidal effect against $S$. aureus ATCC® 43300 $\left(\mathrm{MBC}=2048 \mu \mathrm{g} \mathrm{mL}{ }^{-1}\right)$, which indicates that HPE method is more efficient than Soxhlet in what concerns antibacterial potential of the ensuing diterpene rich extracts. The higher content in diterpenes may explain the antibacterial activity obtained.

Table 5 Antibacterial activity of $B$. bifurcata Soxhlet and optimized HPE extracts expressed in MIC and $\mathrm{MBC}(\mu \mathrm{g} \mathrm{mL})^{-1}$

\begin{tabular}{lll}
\hline & S. aureus ATCC 84300 & \\
\cline { 2 - 3 } & $\operatorname{MIC}\left(\mu \mathrm{g} \mathrm{mL}{ }^{-1}\right)$ & $\mathrm{MBC}\left(\mu \mathrm{g} \mathrm{mL}^{-1}\right)$ \\
\hline Soxhlet extract & 2048 & $>2048$ \\
HPE extract & 1024 & 2048
\end{tabular}

${ }^{a}$ HPE - high pressure extraction; MIC - minimal inhibitory concentration; MBC - minimal bactericidal concentration. 
Table 6 Synergistic potential between B. bifurcata HPE extract and antibiotics: rifampicin, gentamicin, tetracycline and ampicillin, in a concentration range from 2 to $256 \mu \mathrm{g} \mathrm{mL}^{-1}$, expressed as MIC ( $\mu \mathrm{g}$ $\mathrm{mL}^{-1}$ ) against Staphylococcus aureus ATCC $® 43300^{a}$

\begin{tabular}{|c|c|c|}
\hline & $\operatorname{MIC}\left(\mu \mathrm{g} \mathrm{mL}^{-1}\right)$ & FICI \\
\hline Rif & 16 & $<0.125$ (S) \\
\hline Rif + HPE ext & $<2$ & \\
\hline Gent & $>256$ & $<0.125$ (S) \\
\hline Gent + HPE ext & 32 & \\
\hline Tetra & $>256$ & $<0.125(\mathrm{~S})$ \\
\hline Tetra + HPE ext & $<2$ & \\
\hline Amp & 128 & $0.125(\mathrm{~S})$ \\
\hline Amp + HPE ext & 16 & \\
\hline \multicolumn{3}{|c|}{$\begin{array}{l}{ }^{a} \text { HPE ext - high pressure extract; Rif - rifampicin; Gent }- \text { gentamicin; } \\
\text { Tetra - tetracycline; Amp - ampicillin; MIC }- \text { minimal inhibitory } \\
\text { concentration; FICI }- \text { factorial inhibitory concentration index; } \\
\text { synergistic (S) if FICI } \leq 0.5 \text {; partially synergistic (PS), if } 0.5<\text { FICI }<1 \text {; } \\
\text { additive (ADD), if FICI }=1 \text {; indifferent (IND), if } 1<\text { FICI } \leq 4 \text { and } \\
\text { antagonistic (ANT), if FICI }>4 \text {. }\end{array}$} \\
\hline
\end{tabular}

The combination of the HPE extract with distinct antibiotics resulted in a considerable decrease of antibiotic MICs values against the $S$. aureus ATCC® 43300. Outstanding decreases were observed with gentamicin and tetracycline, which MIC values decreased from $>256 \mu \mathrm{g} \mathrm{mL}^{-1}$ to 32 and $<2 \mu \mathrm{g} \mathrm{mL}{ }^{-1}$, respectively. Regarding FICI values, performed according to eqn (3), $B$. bifurcata HPE extract with antibiotics resulted in a synergistic effect against $S$. aureus ATCC® 43300. HPE extract, obtained at optimal conditions, shows thus high potential to be further studied as a possible strategy to eradicate $S$. aureus. ${ }^{5}$

The possible use of natural compounds as coadjuvants in conventional antibiotherapy has already been described. ${ }^{\mathbf{4 5 , 4 6}}$ Since their structures are quite different from those of antibiotics, the mechanism of action and/or target may be different and, therefore, other pathways/targets might be involved in bactericidal effect. This fact leads to better outcomes such as enhanced efficacy, decreased dosage and delayed development of drug resistance. ${ }^{45}$ Given the favourable results obtained, it would be of interest to better understand the mechanism against bacterial cells as well as to assess effectiveness over time of the combinations used.

\section{Conclusions}

In this study it was demonstrated the feasibility of HPE to enhance extraction of linear diterpenes from $B$. bifurcata. In addition, HPE showed to be more selective and efficient than conventional Soxhlet extraction with dichloromethane. The effect of pressure, ethanol percentage and time of extraction were evaluated and the HPE conditions were optimized using RSM. HPE optimal conditions achieved were: extraction pressure - $600 \mathrm{MPa}$; ethanol percentage - 80\%; and extraction time $5 \mathrm{~min}$. At these conditions, the B. bifurcata extract presented a DC of $612.2 \pm 10.6 \mathrm{mg} \mathrm{g}^{-1}$ of extract, which is 12.2 -fold higher than Soxhlet extraction (50.1 $\mathrm{mg} \mathrm{g}^{-1}$ of extract). In the same way, the DC in a dw basis was considerably higher in HPE, accounting for $38954 \pm 633\left(\mathrm{mg} \mathrm{kg}^{-1} \mathrm{dw}\right)$, which is 6.1-fold than that obtained with Soxhlet extraction (6394 $\mathrm{mg} \mathrm{kg}^{-1} \mathrm{dw}$ ). HPE at optimal conditions also resulted in an extract with considerably higher antioxidant and antibacterial activities and a synergism with distinct antibiotics was also observed. Therefore, HPE shows to be a promising technique to obtain $B$. bifurcata extracts with potential to be used in pharmaceutical or biomedical applications, particularly in the management of antibiotic-resistant pathogenic bacteria.

\section{Conflicts of interest}

There are no conflicts to declare.

\section{Acknowledgements}

Thanks are due to the University of Aveiro and FCT/MCT for the financial support for the CICECO (FCT UID/CTM/50011/2019) and QOPNA (FCT UID/QUI/00062/2019) research Units through national founds and, where applicable, co-financed by the FEDER, within the PT2020 Partnership Agreement. This work was also funded through FCT under the Project UID/AGR/ $00115 / 2019$ to ICAAM. S. A. O. Santos thanks the AgroForWealth: Biorefining of agricultural and forest by-products and wastes: integrated strategic for valorisation of resources towards society wealth and sustainability project (CENTRO-010145-FEDER-000001), funded by Centro2020, through FEDER and PT2020 for the contract. P. A. B. Ramos acknowledges the "MultiBiorefinery" project (POCI-01-0145-FEDER-016403) for her post-doctoral grant.

\section{Notes and references}

1 E. Hussain, L. J. Wang, B. Jiang, S. Riaz, G. Y. Butt and D. Y. Shi, RSC Adv., 2016, 6, 12592-12610.

2 J. Muñoz, G. Culioli and M. Köck, Phytochem. Rev., 2013, 12, 407-424.

3 C. Alves, S. Pinteus, T. Simões, A. Horta, J. Silva, C. Tecelão and R. Pedrosa, Int. J. Food Sci. Technol., 2016, 51, 1638-1646.

4 L. Pereira, As Algas Marinhas e Respectivas Utilidades, Universidade de Coimbra, 2008, vol. 913, pp. 1-19.

5 S. Santos, S. Trindade, C. Oliveira, P. Parreira, D. Rosa, M. Duarte, I. Ferreira, M. Cruz, A. Rego, M. Abreu, S. Rocha and A. Silvestre, Mar. Drugs, 2017, 15, 340.

6 K. Le Lann, J. Rumin, S. Cérantola, G. Culioli and V. StigerPouvreau, J. Appl. Phycol., 2014, 26, 1207-1214.

7 R. Valls, L. Piovetti, B. Banaigs, A. Archavlis and M. Pellegrini, Phytochemistry, 1995, 39, 145-149.

8 R. Valls, B. Banaigs, L. Piovetti, A. Archavlis and J. Artaud, Phytochemistry, 1993, 34, 1585-1588.

9 G. Culioli, M. Daoudi, V. Mesguiche, R. Valls and L. Piovetti, Phytochemistry, 1999, 52, 1447-1454.

10 G. Culioli, M. Daoudi, A. Ortalo-Magné, R. Valls and L. Piovetti, Phytochemistry, 2001, 57, 529-535.

11 G. Culioli, A. Ortalo-Magné, M. Richou, R. Valls and L. Piovetti, Biochem. Syst. Ecol., 2002, 30, 61-64. 
12 Q. Göthel, J. Muñoz and M. Köck, Phytochem. Lett., 2012, 5, 693-695.

13 G. Culioli, A. Ortalo-Magné, M. Daoudi, H. Thomas-Guyon, R. Valls and L. Piovetti, Phytochemistry, 2004, 65, 2063-2069.

14 S. Pinteus, J. Silva, C. Alves, A. Horta, N. Fino, A. I. Rodrigues, S. Mendes and R. Pedrosa, Food Chem., 2017, 218, 591-599.

15 E. M. Balboa, E. Conde, A. Moure, E. Falqué and H. Domínguez, Food Chem., 2013, 138, 1764-1785.

16 V. Smyrniotopoulos, C. Merten, M. Kaiser and D. Tasdemir, Mar. Drugs, 2017, 15, 1-10.

17 E. M. C. Alexandre, L. M. G. Castro, S. A. Moreira, M. Pintado and J. A. Saraiva, Food Eng. Rev., 2017, 9, 1-23.

18 E. M. C. Alexandre, S. Silva, S. A. O. Santos, A. J. D. Silvestre, M. F. Duarte, J. A. Saraiva and M. Pintado, Food Res. Int., 2019, 115, 167-176.

19 H. W. Huang, C. P. Hsu, B. B. Yang and C. Y. Wang, Trends Food Sci. Technol., 2013, 33, 54-62.

20 H. Mújica-Paz, A. Valdez-Fragoso, C. T. Samson, J. WeltiChanes and A. Torres, Food Bioprocess Technol., 2011, 4, 969-985.

21 V. M. Balasubramaniam, S. I. Martínez-Monteagudo and R. Gupta, Annu. Rev. Food Sci. Technol., 2015, 6, 435-462.

22 V. Briones-Labarca, M. Plaza-Morales, C. Giovagnoli-Vicuña and F. Jamett, LWT-Food Sci. Technol., 2015, 60, 525-534.

$23 \mathrm{X}$. Jun, High Pressure Res, 2006, 26, 33-41.

24 J. Xi, Chem. Eng. Technol., 2006, 29, 736-739.

25 G. Ruiz-Montañez, J. A. Ragazzo-Sánchez, M. CalderónSantoyo, G. Velázquez-De La Cruz, J. A. Ramírez De León and A. Navarro-Ocaña, Food Chem., 2014, 159, 267-272.

26 X. Jun, Crit. Rev. Food Sci. Nutr., 2013, 53, 837-852.

27 D. Rodrigues, A. C. Freitas, R. Queirós, T. A. P. Rocha-Santos, J. A. Saraiva, A. M. P. Gomes and A. C. Duarte, J. Food Process. Preserv., 2017, 41, 1-12.

28 S. A. O. Santos, C. S. D. Oliveira, S. S. Trindade, M. H. Abreu, S. S. M. Rocha and A. J. D. Silvestre, J. Appl. Phycol., 2016, 28, 3151-3158.

29 R. Touati, S. A. O. Santos, S. M. Rocha, K. Belhamel and A. J. D. Silvestre, Ind. Crops Prod., 2015, 69, 238-243.
30 J. B. Patel, F. R. Cockerill and P. A. Bradford, Performance standards for antimocrobial susceptibility testing: twenty-fifth informational supplement, Clinical and Laboratory Standards Institute, Wayne, PA, USA, 2015, vol. 35.

31 I. Wiegand, K. Hilpert and R. E. W. Hancock, Nat. Protoc., 2008, 3, 163-175.

32 T. L. Riss, A. L. Niles and L. Minor, Assay Guid. Man., 2004, 123.

33 V. Pereira, C. Dias, M. C. Vasconcelos, E. Rosa and M. J. Saavedra, Ind. Crops Prod., 2014, 52, 1-7.

34 P. Kumari, M. Kumar, V. Gupta, C. R. K. Reddy and B. Jha, Food Chem., 2010, 120, 749-757.

35 A. Ortalo-Magné, G. Culioli, R. Valls, B. Pucci and L. Piovetti, Phytochemistry, 2005, 66, 2316-2323.

36 M. Daoudi, S. Bakkas, G. Culioli, A. Ortalo-Magné, L. Piovetti and M. D. Guiry, Biochem. Syst. Ecol., 2001, 29, 973-978.

37 G. Culioli, V. Mesguiche, L. Piovetti and R. Valls, Biochem. Syst. Ecol., 1999, 27, 665-668.

38 J. Hu, B. Yang, X. Lin, X.-F. Zhou, X.-W. Yang and Y. Liu, Handbook of Marine Macroalgae, John Wiley \& Sons, Ltd, Chichester, UK, 2011.

39 E. M. C. Alexandre, P. Araújo, M. F. Duarte, V. de Freitas, M. Pintado and J. A. Saraiva, Food Bioprocess Technol., 2017, 10, 886-900.

40 E. M. C. Alexandre, P. Araújo, M. F. Duarte, V. de Freitas, M. Pintado and J. A. Saraiva, J. Food Sci. Technol., 2017, 54, 2519-2531.

41 E. Puértolas, G. Saldaña, I. Álvarez and J. Raso, Food Chem., 2011, 126, 1482-1487.

42 S. L. Holdt and S. Kraan, J. Appl. Phycol., 2011, 23, 543-597.

43 T. N. Zvyagintseva, N. M. Shevchenko, A. O. Chizhov, T. N. Krupnova, E. V. Sundukova and V. V. Isakov, J. Exp. Mar. Biol. Ecol., 2003, 294, 1-13.

44 R. Touati, S. A. O. Santos, S. M. Rocha, K. Belhamel and A. J. D. Silvestre, Ind. Crops Prod., 2015, 76, 936-945.

45 M. Ayaz, F. Ullah, A. Sadiq, F. Ullah, M. Ovais, J. Ahmed and H. P. Devkota, Chem.-Biol. Interact., 2019, 308, 294-303.

46 M. Simoes, S. Rocha, M. Coimbra and M. Vieira, Med. Chem., 2008, 4, 616-623. 